\title{
An Efficient Method for Isolation of Hantaan Virus through Serial Passages in Suckling Mice
}

\author{
J.-L. Li J.-X.Ling L.-J.Chen F. Wei F.Luo Y.-Y. Liu H.-R. Xiong W. How
}

Z.-Q. Yang

State Key Laboratory of Virology, Institute of Medical Virology, School of Medicine, Wuhan University, Wuhan, PR China

\section{Key Words}

Hantavirus · Hantaan virus · Virus isolation $\cdot$ Suckling mice inoculation of suckling mice with suspected hantavirus-infected rodent samples is an efficient method for isolation and maintenance of HTNV.

Copyright $\odot 2013$ S. Karger AG, Basel

\begin{abstract}
Objective: Hantaan virus (HTNV) is one of the main etiologic agents for hemorrhagic fever with renal syndrome in China. However, it is very difficult to isolate the virus from its original host, which hampers the viral characterization. This study describes an efficient method for isolating HTNV in suckling mice. Methods: Hantavirus-infected Apodemus agrarius were screened by quantitative real-time PCR. The homogenates of one positive rodent lung tissue were inoculated into suckling mice for virus propagation through serial passages. Results: During the three passages in suckling mice, the number of viral RNA copies/nanogram of GAPDH mRNA increased significantly ranging from 477 to 7,278 and 46 to 4,898 in the tissues of brain and lung, respectively. Hantaviral antigens could be detected by indirect immunofluorescence assay and around 100-nm virion-like structures were also observed in brain tissue by transmission electron microscopy. No nucleotide exchange was found except for one in the $3^{\prime}$-non-coding domain of $\mathrm{S}$ segment when comparing the complete genome sequences from hantavirus in the first and the third passages. Conclusion: These results suggest
\end{abstract}

\section{Introduction}

Hantaviruses (genus hantavirus, family Bunyaviridae) contain a tri-segmented, single-stranded, negative sense RNA genome encoding three proteins: nucleocapsid protein (NP), two glycoproteins (Gn, Gc) and RNA polymerase [1]. Rodents and Soricomorpha species are considered as the natural hosts of hantaviruses. A recent study indicated that bats might act as a potential reservoir host for hantavirus $[2,3]$. Several hantaviruses are pathogenic for humans. Infection with Old World hantaviruses circulating in Asia and Europe can cause hemorrhagic fever with renal syndrome (HFRS), whereas infection with New World viruses in North and South America can result in hantavirus pulmonary syndrome when spread to humans via inhalation of virions in excrements and saliva [4-6].

Currently, twenty-three hantavirus species have been identified around the world and each rodent-borne hantavirus species appears to be associated primarily with

\section{KARGER}

E-Mail karger@karger.ch

www.karger.com/int
(C) 2013 S. Karger AG, Basel

0300-5526/13/0563-0172\$38.00/0
Z.-Q. Yang

Institute of Medical Virology

School of Medicine, Wuhan University

185 Donghu Road, Wuhan 430071 (PR China)

E-Mail zqyang@whu.edu.cn 
one or a few closely related rodent species [7]. Among rodent-borne hantaviruses, Hantaan virus (HTNV) is one of main causative agents of HFRS in Asia, especially in China $[8,9]$. HFRS poses a serious public health problem in China and HTNV has been found in all Chinese provinces except Xinjiang. The natural host of HTNV is the striped field mouse (Apodemus agrarius) [10], although HTNV has been found in Apodemus peninsulae mouse in northeastern China as well [11].

Based on the accumulated HTNV genome sequences, viruses have been divided into at least 9 genetic lineages in China $[9,12]$. Nevertheless, few studies have focused on the biological properties of different HTNV lineages due to the problem that hantavirus is difficult to isolate.

For HTNV, various animal studies, specifically those involving adult ICR and $\mathrm{BALB} / \mathrm{c}$ mice, show that the manifestations are transit and asymptomatic during the infection process in the laboratory $[13,14]$. However, newborn mice are susceptible to HTNV infection with lethal outcome $[15,16]$. Therefore, suckling mice may be a suitable animal model for isolation of hantaviruses from their natural host. Herein, this study shows an efficient method for isolating hantaviruses via inoculation of hantavirus-positive samples to newborn BALB/c mice (48-72 h old). One HTNV strain was successfully isolated from $A$. agrarius captured in an epidemic area in Hubei, China. In addition, genetic and morphological properties of this HNTV strain were analyzed.

\section{Materials and Methods}

\section{Virus Isolation}

The hantavirus-positive $A$. agrarius were collected from Jiangxia District - a HFRS endemic area in Hubei Province, China [17]. The lung tissues of positive A. agrarius were harvested and homogenized to $10 \%(\mathrm{w} / \mathrm{v})$ suspensions in the Dulbecco's modified Eagle's medium. The homogenates were frozen and thawed three times and centrifuged at $3,000 \mathrm{rpm}$ for $15 \mathrm{~min}$ at $4^{\circ}$. Supernatants from the homogenates were used to inoculate intracranially into the neonatal BALB/c mice (about $72 \mathrm{~h}$ old) as previously described [18]. The mice were sacrificed when obvious clinical symptoms were observed or 30 days post-infection. The tissues of brain, heart, lung and kidney were taken from all the mice for screening by indirect immunofluorescence assay (IFA) and RT-PCR as previously described [18]. The brain tissue of 1 positive-BALB/c mouse from the previous passage was taken, homogenized and used to inoculate another suckling BALB/c mice for virus propagation for the next passage. Three serial passages were carried out by this method. About 8 suckling BALB/c mice were used to inoculate with virus for each passage. All the animal manipulations were performed in the Animal Biosafety Level 3 Laboratory of the Animal Research Center at Wuhan University and were approved by the Institutional Animal Care and Use Committee.

\section{Indirect IFA}

Hantavirus antigens in the lung and brain tissues of mice were detected by IFA as previously described [18]. Briefly, the frozen sections of lung and brain tissues of mice were firstly processed with rabbit anti-HTNV/76-118 antibodies (1:200 dilution). Fluorescein isothiocyanate-labeled goat anti-rabbit IgG (1:50 dilution; Sigma, St. Louis, Mo., USA) were used as the secondary antibodies. Finally, the samples were observed under a fluorescence microscope (Olympus CX-41, Japan).

\section{Electron Microscopy}

Brain tissues were fixed with $2.5 \%$ glutaraldehyde, post-fixed in $1 \% \mathrm{OsO}_{4}$ (diluted by phosphate-buffered solution) and embedded in Epon 812. Thin sections were stained by lead and uranyl acetate and examined under the electron microscope (Tecnai, G2 20 TWIN, The Netherlands) at $200 \mathrm{kV}$.

\section{Quantitative Real-Time PCR}

Total RNA was extracted from tissues of heart, brain, lung and kidney using Trizol reagent (Invitrogen, Carlsbad, Calif., USA) according to the manufacturer's protocol. First-strand cDNA was generated using random primer (Sangon, Shanghai, China) and M-MLV reverse transcriptase (Promega, Madison, Wisc., USA). Each cDNA sample from various organs of infected BALB/c mice inoculated with strain HV004 [17] was tested by quantitative realtime PCR in triplicate. The $20-\mu l$ reaction mixture contained $1 \mu \mathrm{l}$ of cDNA, $10 \mu \mathrm{l}$ SYBR Green real-time PCR Master Mix (Toyobo, Tokyo, Japan), $0.2 \mu \mathrm{M}$ forward primer-tsf (5'-TCTAGTTGTATCCCCATCGACTG-3') and $0.2 \mu \mathrm{M}$ reverse primer-tsr (5'-ACATGCGGAATACAATTATGGC-3'). PCR cycling conditions consisted of incubations at $95^{\circ}$ for 3 min followed by 40 cycles at $95^{\circ}$ for $10 \mathrm{~s}, 60^{\circ}$ for $10 \mathrm{~s}$ and $72^{\circ}$ for $10 \mathrm{~s}$. Rodent glyceraldehyde-3-phosphate dehydrogenase (GAPDH) mRNA expression was used as a normalization control. Each $20-\mu$ l reaction mixture contained $1 \mu \mathrm{l}$ of cDNA, $10 \mu \mathrm{l}$ of SYBR Green real-time PCR Master Mix and $0.2 \mu \mathrm{M}$ rodent GAPDH forward primer (5'-ACACATTGGGGGTAGGAACA- $3^{\prime}$ ) and reverse primer (5'-ACCCAGAAGACTGTGGATGG-3'). The levels of viral genome and GAPDH mRNA were quantified from the standard curve. The results were expressed as the ratio of the copy number of viral RNA to nanograms of GAPDH mRNA.

\section{Sequence Determination}

First-strand cDNA was generated from total RNA extracted from the infected BALB/c mice. Several pairs of primers were used to amplify and determine $S, M$ and $L$ segment sequences, respectively [17]. The exact nucleotide sequences of the $5^{\prime}$ and $3^{\prime}$ termini of the virus S, $M$ and $L$ segment were determined by the RNA ligation method described previously [19]. RT-PCR products were gel-purified and sequenced with an ABI 3730 automatic sequencer (Applied Biosystems).

\section{Sequence Comparison and Phylogenetic Analysis}

Hantavirus nucleotide and amino acid sequences were compared using ClustalX 2.0 [20] with default parameters and revised with BioEdit 7.0 manually. The phylogenetic tree was constructed using the neighbor-joining method with a bootstrap of 1,000 replicates in the MEGA program (version 5) [21]. 


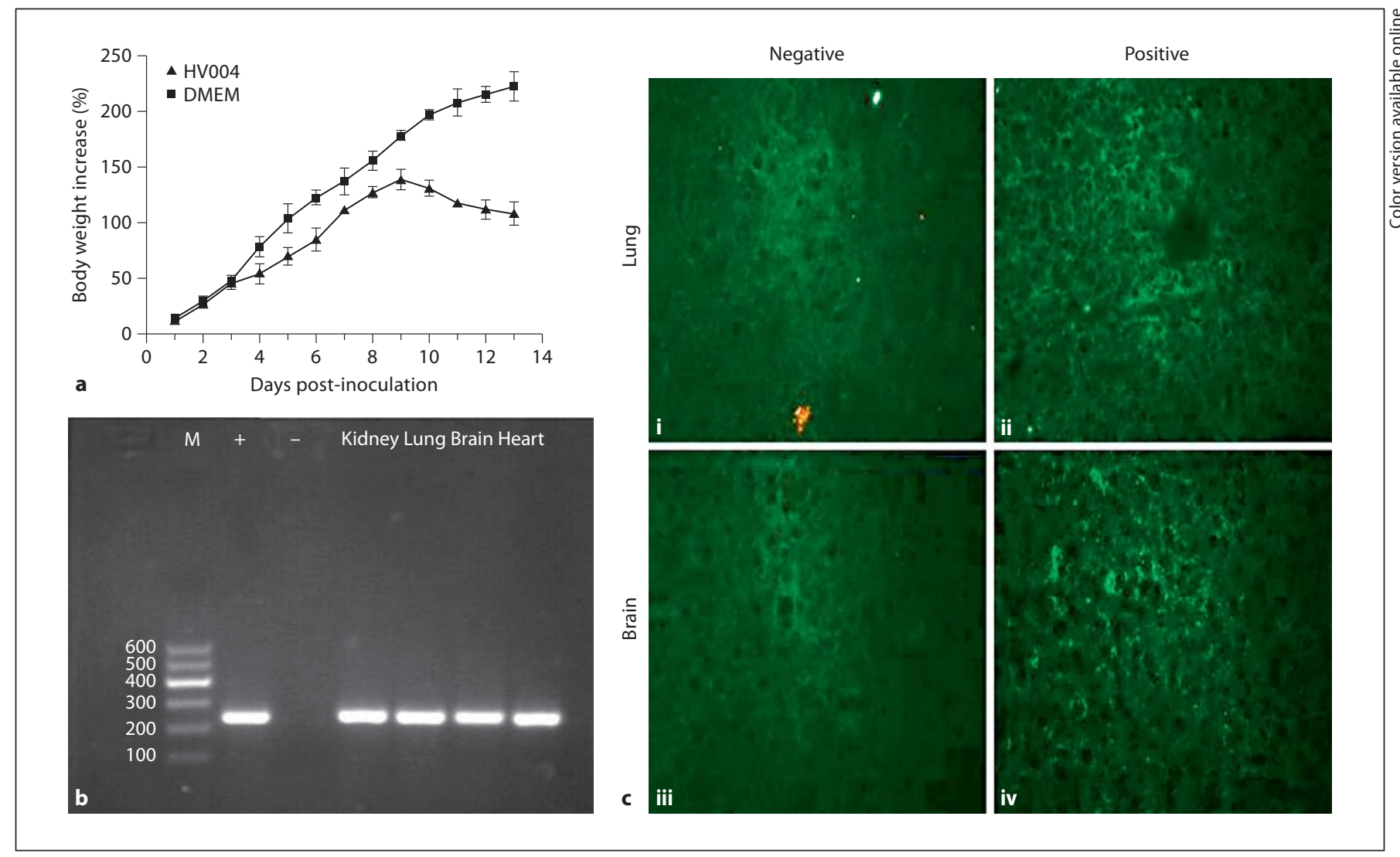

Fig. 1. Body weight change, detection of hantaviral antigens and nucleic acid of the suckling mice inoculated with strain HV004. a Body weight changes of hantavirus-infected BALB/c mice $(\mathrm{n}=$ 7) in the third passage. Body weight increase is expressed as the increased percentage of body weight on the day before inoculation. b RT-PCR results of the HV004-infected tissue (brain, lung, heart and kidney) in the third passage. Identified hantaviral

Table 1. Isolation of hantavirus in suckling mice through serial passages

\begin{tabular}{|c|c|c|c|c|}
\hline \multirow[t]{2}{*}{ Passage } & \multirow{2}{*}{$\begin{array}{l}\text { Suckling } \\
\text { mice, } n\end{array}$} & \multicolumn{2}{|c|}{ Death of suckling mice } & \multirow{2}{*}{$\begin{array}{l}\text { Hantavirus } \\
\text { S segment (927nt-1168) } \\
\text { positive, } n\end{array}$} \\
\hline & & d.p.i. & $\mathrm{n}$ & \\
\hline One & 7 & - & - & 1 \\
\hline Two & 6 & 16 & 1 & 6 \\
\hline Three & 7 & 13 & 3 & 7 \\
\hline
\end{tabular}

-: No death of a suckling mouse was found.
RNA was used as the template of RT-PCR for positive (+) and hantaviral negative RNA for the negative (-) controls. c Detection of hantaviral antigens by indirect IFA. Lung (ii) and brain (iv) came from the mouse inoculated with strain HV004 in the third passage. Non-infected tissue lung (i) and brain (iii) were used as controls. Magnification $\times 400$ for brain tissue and $\times 200$ for lung tissue.

\section{Results}

\section{Isolation of Hantavirus in BALB/c Suckling Mice}

Partial S segment of hantavirus was detected by quantitative real-time PCR from 3 A. agrarius [18]. Seven suckling $\mathrm{BALB} / \mathrm{c}$ mice were inoculated intracerebrally with lung homogenates from $1 \mathrm{~S}$ segment-positive $A$. agrarius (table 1). Initially, no lethal case was observed at 30 days post-infection (d.p.i.) in the first passage. However, partial S segments of hantavirus could be detected in the tissues of heart, brain, lungs and kidneys in $1 \mathrm{BALB} / \mathrm{c}$ mouse (1/7). In the second passage, one out of 6 suckling mice was dead at 16 d.p.i. and other mice showed obvious symptoms with weight loss, reduced activity and ruffled fur (data not shown). In addition, S seg- 
ment sequences were determined in all 6 inoculated animals. Brain and lung tissues of these suckling mice were found to be antigen positive by IFA with rabbit antiHTNV/76-118 serum.

In the third passage, the suckling mice showed reductions in body weight around 10 d.p.i. (fig. 1a). Three out of 7 newborn mice died at 13 d.p.i. and the rest died at 14 d.p.i. with apparent symptoms including weight loss, transient state of hyperactivity and ruffled appearance of their coats accompanied by hunched posture and progressively diminishing mobility. Paralysis of both hind limbs appeared prior to death. IFA and RT-PCR were used to detect the distribution of viral antigen and RNA in different tissues. The partial S segment sequence could be detected in the tissues of brain, heart, lung and kidney by RT-PCR (fig. 1b). The viral antigen could be observed in the tissues of lung and brain under fluorescence microscope. The scattered, granular and green fluorescence was regarded as the viral protein which was located in hantavirus-infected tissue (fig. 1c). As a result, one strain of hantavirus that we designated as HV004 was successfully isolated by three successive passages in the suckling mice.

\section{Electron Microscopy}

The ultrastructure of HV004-infected brain from passage three was analyzed by transmission electron microscopy (fig. 2). Virion-like structures, likely with a bilayered envelope were noticed in brain tissue. Its diameter ranged from 91.8 to $117.82 \mathrm{~nm}$.

\section{Viral Load in Organs from Different Passages}

To exam the virus load during the different passages of isolation, the tissue samples of heart, brain, lung and kidney were collected from the mice from passages one to three and the viral RNA was determined by quantitative real-time RT- PCR. From these passages, the level of the viral RNA in brain and lung samples increased dramatically from 477 to 7,278 and 46 to 4,898 viral RNA copies/nanogram of GAPDH mRNA, respectively (fig. 3). Compared with the brain and lung tissues, the viral load raised slightly in the heart and kidney tissues during the passages. At each passage, more viral RNA was detected in brain and lung than in heart and kidney tissues.

\section{Comparison of Viral Genome Sequences}

The complete S, M and L sequences of strain HV004 were determined. Phylogenic analysis showed that strain HV004 belonged to HTNV and represented a new subtype [17]. To determine whether there were any nucleo-

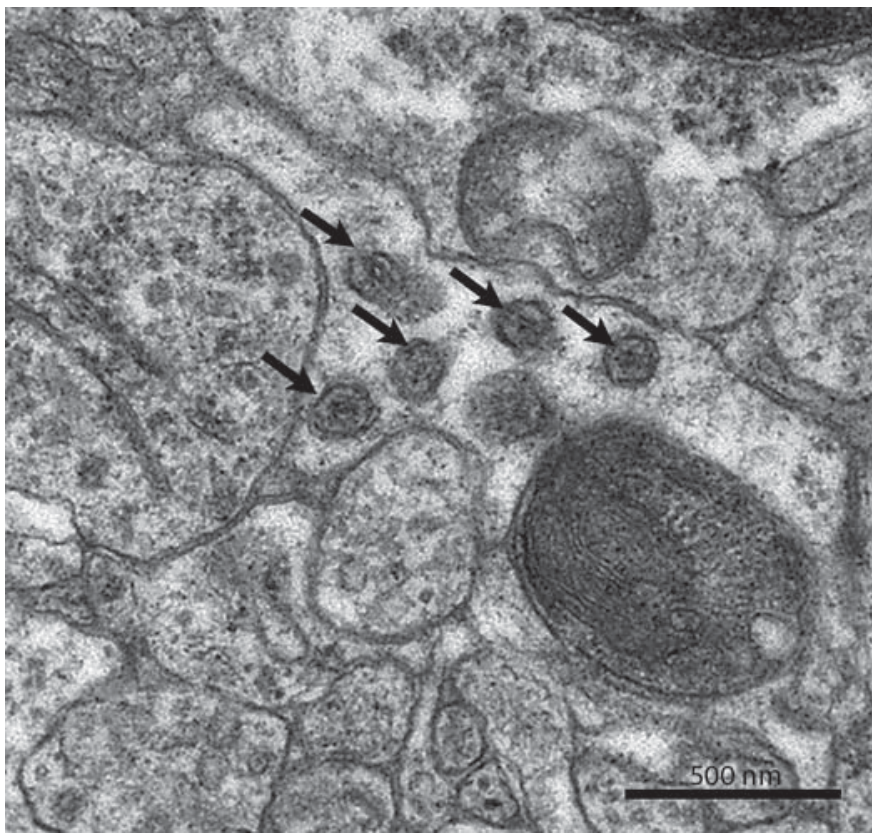

Fig. 2. The electron micrograph of strain HV004 virion in the brain tissue of BALB/C mouse. The arrowheads show virus particles.

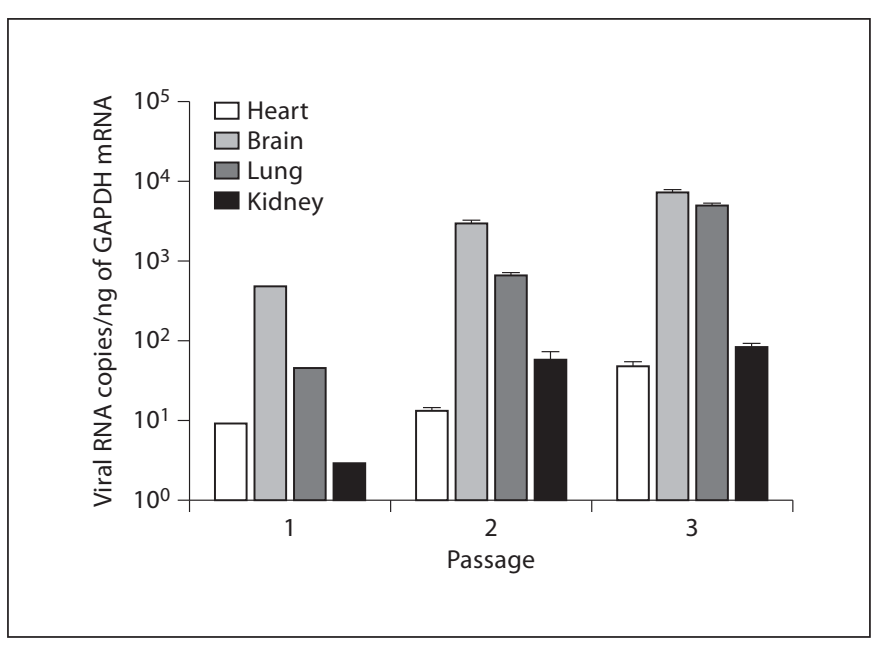

Fig. 3. Viral loads of suckling BALB/c mice in different passages of virus propagation. The viral load in each organ was measured by quantitative real-time PCR and is expressed as the mean of all positive organs of suckling mice from different passages (passage one, $1 \mathrm{BALB} / \mathrm{c}$ mouse sacrificed at $30 \mathrm{~d}$.p.i; passage two, 3 sacrificed at 16 d.p.i., and passage three, 3 sacrificed at 14 d.p.i). Error bars represent the standard deviation. 
tide exchanges during the isolation process, the whole genome sequences of HV004 from passages one to three were compared. No mutation was found except for a single nucleotide exchange from $\mathrm{G}$ (passage one) to A (passage three) at position 1392 in the $3^{\prime}$-non-coding domain of $S$ segment.

\section{Discussion}

It is known that hantaviruses are very difficult to isolate from the natural host. Usually, Vero-E6 cells are applied to isolate hantavirus due to deficiency in expression of IFN-I and IFN-II. However, it is not an easy task to make hantavirus adapt from their natural host to VeroE6 cells. In addition, during the passage in the cell culture, it is very likely that some of the original characteristics of hantaviruses will be changed by the accumulation of mutations in the viral genome [22, 23]. In this study, we isolated HV004 successfully through the sequential inoculation of suckling mice. By this method, hantavirus could propagate well in the target organs and tissues. Also, we employed the suckling BALB/c mice to compare the virulence of the hantavirus from the first and third passages - no virulence difference was found between them except for a single nucleotide exchange (data not shown). This suggests that during the process of isolation, the suckling mice model keeps the original state of hantavirus.

Though several animals can be infected by hantavirus via some inoculation routes, the susceptibility levels vary widely. The susceptibility of animals to hantaviruses correlated well with the genetic relationships of the animals to the natural reservoirs of hantaviruses [24]. BALB/c, the laboratory inbred mice, is derived from Mus musculus which is more closely related to Apodemus mice than to voles [25]. Therefore, it may be that BALB/c mouse is more suitable for inoculation and isolation of HTNV than hantaviruses derived from voles. A recent study indicated that inoculation of Syrian hamsters with rodent samples was an efficient method for the isolation and maintenance of Puumala virus [26]. However, hamsters are more distantly related to Myodes glareolus (the natural host of Puumala virus), which is more likely to lead to the low susceptibility for the infection [24]. So, whether other factors (e.g. ages of animals, methods of inoculation) influence the susceptibility of rodents to hantaviruses other than the genetic relationship of the used animal to the natural reservoir host still needs to be addressed.
Because no suitable disease model is available for HTNV study [27], suckling BALB/c mice are still applied in animal experiments for HTNV, especially in aspect of virulence. So the hantaviruses isolated from $B A L B / c$ mice could be directly used as virus stocks for the animal experiment on $\mathrm{BALB} / \mathrm{c}$ mice without adaptation again.

So far, based on the genetic analysis of the small and medium genome segments, at least 9 distinct lineages of HTNV and 6 distinct lineages of Seoul virus (SEOV) are circulating in China. Recently, several new lineages of HTNV and SEOV were detected in the Hubei province or elsewhere in China $[12,28]$. However, biological properties of these novel HTNV and SEOV lineages such as virulence, pathogenicity and interaction with immunity system are still unclear. To solve these questions, the very first step will be the isolation of these hantaviruses, and incubation of the hantavirus-infected tissues from their natural host to $\mathrm{BALB} / \mathrm{c}$ mice provides a good method to recover the virus.

Phylogenetic analysis showed that isolate HV004 belongs to a new HTNV subtype. The diameter of HV004 particles detected in brain tissues is $91.8-117.82 \mathrm{~nm}$, identical to that of other hantavirus strains previously reported $[29,30]$.

For strain HV004, the highest viral load is detected in brain among all the organs when propagating in suckling mice (fig. 2). In this respect, strain HV004 is consistent with that strain B78 or H5 (AMR) other than strain 76118 , which has a higher titer in the lung tissue, though HV004 is closer to HTNV76-118 than B78 or H5 based on the phylogenetic analysis [31]. One of the reasons is probably that we inoculated virus to $B A L B / c$ mice by means of intracerebral routes instead of subcutaneous routes used to inoculate HTNV 76-118, B78 and H5.

In conclusion, inoculation of samples from the natural host of HTNV into suckling mice is an efficient method for isolating HTNV. This method may also be used to isolate rodent-associated hantaviruses and will thereby allow future characterization of the biological properties of hantaviruses.

\section{Acknowledgments}

This work was supported by the National High Technology Research and Development 863 Program of China (No. 2007AA02Z465), grants from the National Natural Science Foundation of China (NSFC project No. 30770096 and 30873104).

We also thank Jeremy Olivier, University of New Mexico, N. Mex., USA, for his valuable advice and great help in adapting the English language.
Li/Ling/Chen/Wei/Luo/Liu/Xiong/How/ Yang 


\section{References}

1 Schmaljohn C, Nichol ST: Bunyaviridae; in Knipe DM, Howley PA (eds): Field's Virology ed 5. Philadelphia, Lippincott-Williams \& Wilkins, 2007, pp 1742-1789.

$\checkmark 2$ Sumibcay L, Kadjo B, Gu SH, Kang HJ, Lim BK, Cook JA, Song JW, Yanagihara R: Divergent lineage of a novel hantavirus in the banana pipistrelle (Neoromicia nanus) in Cote d'Ivoire. Virol J 2012;9:34.

3 Weiss S, Witkowski PT, Auste B, Nowak K, Weber N, Fahr J, Mombouli JV, Wolfe ND, Drexler JF, Drosten C, Klempa B, Leendertz FH, Kruger DH: Hantavirus in bat, Sierra Leone. Emerg Infect Dis 2012;18:159-161.

-4 Jonsson CB, Figueiredo LT, Vapalahti O: A global perspective on hantavirus ecology, epidemiology, and disease. Clin Microbiol Rev 2010;23:412-441.

5 Kruger DH, Ulrich R, Lundkvist A: Hantavirus infections and their prevention. $\mathrm{Mi}-$ crobes Infect 2001;3:1129-1144.

6 Schmaljohn C, Hjelle B: Hantaviruses: a global disease problem. Emerg Infect Dis 1997;3:95-104.

7 Plyusnin A, Beaty BJ, Elliott RM, Goldbach R, Kormelink R, Lundkvist Å, Schmaljohn CS: Bunyaviridae; in King AMQ, Adams MJ, Carstens EB, Lefkowitz EJ (eds): Virus Taxonomy: Classification and Nomenclature of Viruses - Ninth Report of the International Committee on Taxonomy of Viruses. San Diego, Elsevier, 2011, pp 693-709.

$\checkmark 8$ Wang $\mathrm{H}$, Yoshimatsu K, Ebihara $\mathrm{H}$, Ogino M, Araki K, Kariwa H, Wang Z, Luo Z, Li D, Hang C, Arikawa J: Genetic diversity of hantaviruses isolated in China and characterization of novel hantaviruses isolated from Niviventer confucianus and Rattus rattus. Virology 2000;278:332-345.

\2 Zou Y, Hu J, Wang ZX, Wang DM, Li MH, Ren GD, Duan ZX, Fu ZF, Plyusnin A, Zhang YZ: Molecular diversity and phylogeny of Hantaan virus in Guizhou, China: evidence for Guizhou as a radiation center of the present Hantaan virus. J Gen Virol 2008;89: 1987-1997.

10 Song G: Epidemiological progresses of hemorrhagic fever with renal syndrome in China. Chin Med J 1999;112:472-477.

-11 Zhang YZ, Zou Y, Yao LS, Hu GW, Du ZS, Jin LZ, Liu YY, Wang HX, Chen X, Chen HX, Fu ZF: Isolation and characterization of hantavirus carried by Apodemus peninsulae in Jilin, China. J Gen Virol 2007;88:1295-1301.

12 Zhang YZ, Zou Y, Fu ZF, Plyusnin A: Hantavirus infections in humans and animals, China. Emerg Infect Dis 2010;16:1195-1203.
13 Asada H, Tamura M, Kondo K, Okuno Y, Takahashi Y, Dohi Y, Nagai T, Kurata T, Yamanishi K: Role of $t$ lymphocyte subsets in protection and recovery from Hantaan virus infection in mice. J Gen Virol 1987;68:19611969.

14 Kariwa H, Kamimura M, Arikawa J, Yoshimatsu K, Takashima I, Hashimoto N: Characterization of the mode of Hantaan virus infection in adult mice using a nested reverse transcriptase polymerase chain reaction: transient virus replication in adult mice. $\mathrm{Mi}$ crobiol Immunol 1995;39:35-41.

15 Nakamura T, Yanagihara R, Gibbs CJ Jr, Amyx HL, Gajdusek DC: Differential susceptibility and resistance of immunocompetent and immunodeficient mice to fatal Hantaan virus infection. Arch Virol 1985;86: 109-120.

16 Zhang XK, Takashima I, Mori F, Hashimoto $\mathrm{N}$ : Comparison of virulence between two strains of Rattus serotype hemorrhagic fever with renal syndrome (HFRS) virus in newborn rats. Microbiol Immunol 1989;33:195205.

17 Li JL, Ling JX, Liu DY, Liu J, Liu YY, Wei F, Luo F, Chen W, Zhang YH, Xiong HR, Hou W, Yang ZQ: Genetic characterization of a new subtype of Hantaan virus isolated from a hemorrhagic fever with renal syndrome (HFRS) epidemic area in Hubei Province, China. Arch Virol 2012;157:1981-1987.

18 Deng HY, Luo F, Shi LQ, Zhong Q, Liu YJ, Yang ZQ: Efficacy of arbidol on lethal Hantaan virus infections in suckling mice and in vitro. Acta Pharmacol Sin 2009;30:10151024

19 Bohlman MC, Morzunov SP, Meissner J, Taylor MB, Ishibashi K, Rowe J, Levis S, Enria D, St Jeor SC: Analysis of hantavirus genetic diversity in Argentina: S segment-derived phylogeny. J Virol 2002;76:3765-3773.

20 Larkin MA, Blackshields G, Brown NP, Chenna R, McGettigan PA, McWilliam H, Valentin F, Wallace IM, Wilm A, Lopez R, Thompson JD, Gibson TJ, Higgins DG: Clustal W and Clustal X version 2.0. Bioinformatics 2007;23:2947-2948.

-21 Tamura K, Peterson D, Peterson N, Stecher G, Nei M, Kumar S: MEGA5: molecular evolutionary genetics analysis using maximum likelihood, evolutionary distance, and maximum parsimony methods. Mol Biol Evol 2011;28:2731-2739.

22 Lundkvist A, Cheng Y, Sjolander KB, Niklasson B, Vaheri A, Plyusnin A: Cell culture adaptation of Puumala hantavirus changes the infectivity for its natural reservoir, Clethrionomys glareolus, and leads to accumulation of mutants with altered genomic RNA S segment. J Virol 1997;71:9515-9523.
23 Nemirov K, Lundkvist A, Vaheri A, Plyusnin A: Adaptation of Puumala hantavirus to cell culture is associated with point mutations in the coding region of the $\mathrm{L}$ segment and in the noncoding regions of the $\mathrm{S}$ segment. J Virol 2003;77:8793-8800

24 Klingstrom J, Heyman P, Escutenaire S, Sjolander KB, De Jaegere F, Henttonen H, Lundkvist A: Rodent host specificity of European hantaviruses: evidence of Puumala virus interspecific spillover. J Med Virol 2002;68: 581-588.

25 Vapalahti O, Lundkvist A, Fedorov V, Conroy CJ, Hirvonen S, Plyusnina A, Nemirov K, Fredga K, Cook JA, Niemimaa J, Kaikusalo A, Henttonen H, Vaheri A, Plyusnin A: Isolation and characterization of a hantavirus from Lemmus sibiricus: evidence for host switch during hantavirus evolution. J Virol 1999;73:5586-5592.

26 Seto T, Tkachenko EA, Morozov VG, Tanikawa Y, Kolominov SI, Belov SN, Nakamura I, Hashimoto N, Kon Y, Balakiev AE, Dzagurnova TK, Medvedkina OA, Nakauchi M, Ishizuka M, Yoshii K, Yoshimatsu K, Ivanov LV, Arikawa J, Takashima I, Kariwa H: An efficient in vivo method for the isolation of Puumala virus in Syrian hamsters and the characterization of the isolates from Russia. J Virol Methods 2011;173:17-23.

27 Kruger DH, Schonrich G, Klempa B: Human pathogenic hantaviruses and prevention of infection. Hum Vaccin 2011;7:685-693.

28 Liu J, Liu DY, Chen W, Li JL, Luo F, Li Q, Ling JX, Liu YY, Xiong HR, Ding XH, Hou W, Zhang Y, Li SY, Wang J, Yang ZQ: Genetic analysis of hantaviruses and their rodent hosts in central-south China. Virus Res 2011; 163:439-447.

29 Xu F, Yang Z, Wang L, Lee YL, Yang CC, Xiao SY, Xiao H, Wen L: Morphological characterization of hantavirus HV114 by electron microscopy. Intervirology 2007;50: $166-172$

30 Song JW, Kang HJ, Gu SH, Moon SS, Bennett SN, Song KJ, Baek LJ, Kim HC, O’Guinn ML, Chong ST, Klein TA, Yanagihara R: Characterization of Imjin virus, a newly isolated hantavirus from the Ussuri white-toothed shrew (Crocidura lasiura). J Virol 2009;83: 6184-6191.

-31 Lokugamage K, Kariwa H, Lokugamage N, Iwasa M, Hagiya T, Araki K, Tachi A, Mizutani T, Yoshimatsu K, Arikawa J, Iwasaki T, Takashima I: Comparison of virulence of various hantaviruses related to hemorrhagic fever with renal syndrome in newborn mouse model. Jpn J Vet Res 2004;51:143-149. 